\title{
Doble dependencia: abuelos que cuidan nietos en España
}

\author{
Nuria Badenes Plá \\ Instituto de Estudios Fiscales
}

$M^{\text {a }}$ Teresa López López

Universidad Complutense

<mtlopezl@ccee.ucm.es>
Artikulu honetan ezaugarritu nahi da berauen bilobak zaintzen sarritan gertatutako aitona-amonen 'menpekotasun bikoitza', eta konponbide batzuek ematen dira gaiari aurre egiteko. Oinarri batean, behintzat, ulertzen da aitona-amona horiek zaintzak jasotzeko edota ahalezko zaintzak jasotzeko moduko pertsonak direla, baina, lagundu egiten dute -behintzat, garai baterako- menpeko biloben zaintzan. Artikulu honen xedea da aitona-amona horien inguruko ezagutza hobetzea, eta saiakuntza batzuek iradokitzen dituzte aitona-amona horien eta berauen familien bizi-kalitatea hobetzearren. Horretarako, aztertu dute hezkuntza-prozesuan aitonaamonen rolak nolakoak izan behar duten, aitonaamona zaintzaileak ezagutzeko aldagaiak izendatu dituzte -SHARE izeneko Europako Osasunaren, Zahartzearen eta Erretiratzearen inkestaren datu batzuek baliatuz-, eta aztertu dituzte kolektibo horren bizi-kalitatea hobetzearren segi beharreko gida-printzipioak.

\section{HITZ-GAKOAK:}

familia, aitona-amona, menpekotasuna, familia politika, zaintzaileak.
Este artículo caracteriza la situación de 'doble dependencia' que se produce, en muchos casos, cuando los abuelos cuidan a sus nietos, y presenta algunas soluciones. Estos abuelos son calificados, en primera instancia, como un colectivo perceptor, 0 potencial perceptor, de cuidados, pero que, al mismo tiempo, es cuidador de otras personas dependientes -aunque sea temporalmente-, que son los nietos. El objetivo del artículo es avanzar en el conocimiento de estos abuelos y proponer algunas actuaciones para mejorar su calidad de vida y la de sus familias. Para ello, se analiza el papel que deben jugar los abuelos en el proceso educativo, las variables que definen a los abuelos cuidadores -a través de la explotación de una parte de la Encuesta de Salud, Envejecimiento y Jubilación de Europa (SHARE)- y los principios que deberían regir las políticas públicas de apoyo a este colectivo para mejorar su calidad de vida.

\section{Palabras Clave:}

familia, abuelos, dependencia, políticas de familia, cuidadores. 


\section{Introducción}

Los abuelos son un punto de apoyo muy importante en el cuidado de los niños en las familias europeas. En el caso concreto de España, uno de cada cuatro abuelos que tiene nietos los cuida, lo que supone una presencia menor que la media europea, donde la ratio es más de uno de cada tres, pero los españoles dedican una media de siete horas diarias, dos más que la media europea. Estos resultados tan llamativos han pasado hasta ahora inadvertidos, ya que el fenómeno de los abuelos cuidadores no ha sido estudiado en profundidad, quizá porque el trabajo de las personas mayores en el cuidado de la familia no está reconocido. La sociedad está acostumbrada a pensar en ellas como potenciales receptoras de cuidados, cuando constituyen, sin embargo, un colectivo que los otorga de manera intensa.

Este artículo caracteriza la situación de 'doble dependencia' que se produce, en muchos casos, cuando los abuelos cuidan a sus nietos, y presenta algunas soluciones. Estos abuelos son calificados, en primera instancia, como un colectivo perceptor, o potencial perceptor, de cuidados, pero que, al mismo tiempo, es cuidador de otras personas, que, a su vez, son dependientes, aunque sea temporalmente, y que en este caso son los nietos. El objetivo del artículo es avanzar en el conocimiento de estos abuelos y proponer algunas actuaciones para mejorar su calidad de vida y la de sus familias. Para ello, se analiza cuál es el papel que deben jugar los abuelos en el proceso educativo -que va más allá de los simples cuidados materiales de sus nietos-, cuáles son las variables que definen a los abuelos cuidadores -a través de la explotación de una parte de la Encuesta de Salud, Envejecimiento y Jubilación de Europa (SHARE) - y qué principios deberían regir las políticas públicas de apoyo a este colectivo para mejorar su calidad de vida.

\section{Familia y educación. Papel de los padres y abuelos en el proceso educativo}

La familia, en tanto que institución social, presenta dos ámbitos de actividad totalmente diferentes: el privado y el público. Como es lógico, existen importantes diferencias en las decisiones que se toman en uno y otro, pero todas ellas, en mayor o menor medida, afectan a la configuración y estabilidad de la sociedad.

La familia es una institución social fundamental ${ }^{1}$ que desempeña unas funciones que exigen la puesta en marcha de algunas intervenciones públicas y priva-

${ }^{1}$ Todos los manuales de sociología así la consideran y definen. Por ejemplo, pueden consultarse los de Del Campo y Navarro (1985) o Donati (2003). das, en caso de que concurran circunstancias que le impidan desempeñar tales funciones correctamente, bien porque no tiene medios para ello, o porque se producen lo que pueden denominarse 'fallos de la familia'. Para un correcto desempeño de algunas de ellas, es necesaria la participación y colaboración, no sólo del padre, de la madre y, en su caso, de los hermanos, sino también de otros miembros de la familia extensa, como los abuelos.

En la actualidad, y gracias al importante aumento en la esperanza de vida, es cada vez más frecuente que coexistan varias generaciones de una misma familia. Es un hecho histórico que, en un mismo momento (Sancho Castiello et al., 2007), lleguen a convivir padres, hijos y abuelos; e incluso cada vez hay más familias en las que hay bisabuelos. Esta coexistencia no implica necesariamente la convivencia bajo el mismo techo. Es más, los hogares unipersonales son más frecuentes entre la población de mayor edad, y la dimensión de las familias es cada vez más reducida. Sin embargo, esto no implica necesariamente que disminuya la importancia del apoyo familiar, sino que lo que realmente se ha modificado es la forma de prestar dicho apoyo. La familia sigue siendo central, no desaparecen las relaciones familiares entre generaciones, únicamente dejan de cohabitar en la misma vivienda y se produce lo que algunos autores denominan la "intimidad a distancia” (ibídem).

Esta importancia de la familia como institución social le viene dada, fundamentalmente, por las funciones que lleva a cabo, y por el hecho de que las consecuencias derivadas de su forma de vida y sus decisiones exceden a su ámbito estrictamente privado. Así, en primer lugar, figura la función educativa y de transmisión de valores. Una parte muy importante de lo que somos se lo debemos a la educación que hemos recibido. A través de ésta, nos dotamos de los medios e instrumentos necesarios para afrontar la vida. Es el trabajo y la vivencia diaria de determinados valores, sobre todo en el ámbito de la familia, lo que nos hace adquirir una formación integral como personas, que no se debe identificar sólo con la estrictamente académica. Hay que diferenciar dos tipos de aprendizajes. El primero proviene del ámbito estrictamente académico y se refiere al conocimiento de disciplinas concretas (matemáticas, historia, idiomas). Esta educación juega un papel clave en la formación y es fundamental para avanzar en la mejora de la sociedad. Pero hay un segundo tipo de aprendizaje, que excede al estrictamente académico, y que se logra por la propia experiencia y por la repetición de determinados comportamientos y hábitos que generan actitudes: el aprendizaje de valores.

La familia, muy especialmente el padre, la madre y, por supuesto, los abuelos, juegan un papel especialmente importante en la transmisión de valores, y 
es el espacio más idóneo para su adquisición, fundamentalmente por tres razones. En primer lugar, porque en la familia prima, por encima de todo, el cariño. Y no puede olvidarse que es el afecto lo que inicia o bloquea la adquisición de un valor. Pero la forma de desarrollar la afectividad no es idéntica en todos los miembros de la familia. Los padres siempre expresan y muestran su cariño y afectividad a los hijos en el marco de su papel educativo, lo que les obliga a lograr el equilibrio entre la necesaria exigencia y la forma y el momento de expresar su afecto. Pero los abuelos juegan un papel muy diferente. Ellos ya educaron a sus hijos, y ahora su nuevo papel les debería permitir mantener con sus nietos unas relaciones afectivas más libres y abiertas. Aunque nunca se deja de ser padre o madre, por muchos años que se tengan, los abuelos son padres de sus hijos, pero no de sus nietos. Si los abuelos se ven obligados a desempeñar el papel de padres con sus nietos, estaremos privando a nuestros niños y jóvenes de la riqueza que se deriva de la relación afectiva con sus abuelos, y por tanto, estaremos impidiéndoles convivir con un conjunto de valores que sólo éstos son capaces de transmitir.

Si los niños pasan muchas más horas bajo el cuidado de sus abuelos que bajo el de sus padres, pueden producirse dos situaciones. Puede que los abuelos se vean obligados a ejercer la función educativa que los padres, por falta de tiempo, no pueden desempeñar, lo que les llevará, como acaba de indicarse, a mantener con sus nietos unas relaciones afectivas que no les corresponden, y que les privarán de las ventajas que su presencia como abuelos les proporcionaría. 0 bien, si no son capaces, por edad o salud física o psíquica, de desempeñar el papel de padres, es posible que esos niños presenten carencias educativas importantes. Si bien es cierto que los abuelos se sienten útiles al ayudar a sus hijos en el desempeño de su papel de cuidadores y logran, en muchos casos, disminuir sus problemas de soledad, también es cierto que, al no ejercer el papel de abuelos que les corresponde, estas situaciones pueden producirles situaciones de estrés y efectos negativos sobre su salud, al asumir una responsabilidad ajena. En definitiva, para el correcto desempeño de esta función educativa y de transmisión de valores, es necesario que cada uno de los miembros de la familia desempeñe la función que le corresponde. Dejemos a los abuelos ser abuelos, y a los padres, ser padres.

La segunda función con consecuencias sociales importantes que desempeña la familia es la de socialización primaria. En ella, los niños comienzan a iniciarse en los procesos que les llevan a adquirir comportamientos relativamente duraderos que les permitirán participar en la vida social y contribuir a su desarrollo. Es cierto que actualmente, más que nunca, la socialización se produce de manera colectiva, a través de medios de comunicación, las escue- las o las guarderías. Sin embargo, cada estamento social, cada canal de comunicación y cada sujeto que participa en ella lo hace de manera diferente. Todos son piezas de un rompecabezas en el que cada una resulta imprescindible para construir la figura completa, y si alguna se pierde, el dibujo final quedará incompleto. La familia es el primer lugar de socialización, por tanto, si falta o se sustituye por otro, el resultado final será incompleto. Y en el desempeño de esta función, los abuelos juegan un papel insustituible. Sus conocimientos, su forma de vida, incluso su estado de salud son, en numerosas ocasiones, muy diferentes a los de los padres, por lo que pueden acercar a los nietos a una realidad que, si sólo conviven con los padres, no podrían llegar a conocer.

\section{Si los niños pasan muchas} más horas bajo el cuidado de sus abuelos que bajo el de sus padres, pueden llegar a mantener con sus nietos unas relaciones afectivas que no les corresponden

Así, por ejemplo, el primer contacto de los niños más pequeños con la enfermedad, el sufrimiento, e incluso la soledad y la experiencia de la muerte es frecuente que venga de la mano de los abuelos. Y vivir estas experiencias junto a las personas que más les quieren -padres y abuelos- será siempre positiva, incluso siendo dolorosas, y es seguro que mejorará su proceso de socialización. No deberíamos, pues, impedir a nuestros niños vivir estas y otras muchas experiencias con sus abuelos. Si éstos se ven obligados a ejercer un papel que no les corresponde, el de padres, es posible que los resultados sobre la afectividad y el equilibrio emocional de estos niños no sean los mejores.

Por último, la familia también desempeña una función de enlace de generaciones, ya que no sólo la forman los padres y los hijos, sino también los abuelos, tíos y otros parientes, todos los cuales actúan como una red de solidaridad y apoyo. Las políticas de apoyo a las familias no deben ocuparse sólo de ayudar a éstas mientras los padres y los hijos viven juntos; deben abarcar también otras fases posteriores de su ciclo vital, apoyando la sostenibilidad y desarrollo de todas las relaciones intergeneracionales. Éstas ofrecen una de las mejores formas de transmisión de la cultura. Entender y aceptar a la familia como red de solidaridad intergeneracional es clave para la cohesión social. Pero 
esta solidaridad debe actuar en ambos sentidos, es decir, de padres a hijos y de hijos a padres, y en ella juegan un papel clave los abuelos. En muchas ocasiones, son ellos los que ayudan a los hijos, ya adultos, que permanecen en el hogar familiar hasta edades muy elevadas, y cuando salen de él, continúan ayudándoles en la educación de los hijos.

El cuidado de esta red de solidaridad exige el cuidado de todas y cada una de las personas que la forman, y entre ellas están los abuelos. Los que hoy cuidan a nuestros hijos, si no reciben el cuidado y la atención de todos, pueden llegar a convertirse en personas dependientes. Por tanto, si queremos evitar la dependencia, no tenemos otra opción que cuidar a aquellos que están más cerca de caer en ella: el colectivo de abuelos cuidadores. Esto exige avanzar en el conocimiento de su realidad, y éste es el objetivo de los siguientes epígrafes de este trabajo.

\section{Datos del análisis empírico. La Encuesta de Salud, Envejecimiento y Jubilación en Europa (SHARE)}

La aparición de los datos de la Encuesta de Salud, Envejecimiento y Jubilación en Europa (Survey of Health, Ageing and Retirement in Europe), a la que de ahora en adelante nos referiremos como SHARE, propician una ocasión única para caracterizar muchos de los acontecimientos y las circunstancias ligados a la dependencia y la vejez. Es una base de microdatos que contiene información sobre salud, estado socioeconómico, y redes sociales y familiares de más de 40.000 individuos de 50 y más años de distintos países europeos. España ha participado en la encuesta desde su primera ola, en el 2004, continuó en la segunda, referida al 2006, y seguirá participando, lo que permitirá conocer fenómenos que aparecen en los individuos mayores de nuestro país, y comparar semejanzas y diferencias con países vecinos.

El objetivo que se pretende con su publicación es ofrecer una panorámica multidimensional del proceso de envejecimiento que se está produciendo en Europa. Las variables incluidas se refieren a salud (estado declarado, condiciones físicas y cognitivas, comportamiento saludable, utilización de los servicios sanitarios), marcadores biológicos (índice de masa corporal, fuerza, presión), variables psicológicas (bienestar y satisfacción), variables económicas (actividad laboral, características del empleo, oportunidades de empleo tras la edad de jubilación, fuentes y composición de la renta, riqueza y consumo, vivienda, educación); así como variables referidas al apoyo social (asistencia entre familiares, transferencias de renta y activos, redes sociales, actividades de voluntariado).

Puesto que el interés de este trabajo está centrado en la caracterización del fenómeno de los abuelos cuidadores, presentaremos el resumen del valor por países de determinadas variables que son significativas para explicar dicho cuidado. En particular el porcentaje de abuelos que cuidan a los nietos (sin considerar la intensidad de cuidado), el número medio de nietos, la edad de los hijos más pequeños de cada hijo por tramos (de menos de 4 años, de entre 4 y 10 , y de mayor edad) ${ }^{2}$, el número medio de horas de cuidado al total de los nietos, la distancia media entre abuelos y nietos, y si viven juntos o separados.

\begin{tabular}{|c|c|c|c|c|c|c|c|c|c|}
\hline \multirow[t]{2}{*}{$\begin{array}{l}\text { País } \\
\text { (no casos) }\end{array}$} & \multirow[t]{2}{*}{$\begin{array}{c}\text { Cuidan nietos } \\
\text { (\%) }\end{array}$} & \multirow[t]{2}{*}{$\begin{array}{l}\text { № de } \\
\text { nietos }\end{array}$} & \multirow[t]{2}{*}{$\begin{array}{l}\text { Viven en la } \\
\text { misma casa } \\
(\%)\end{array}$} & \multirow[t]{2}{*}{$\begin{array}{c}\text { Horas } \\
\text { anuales de } \\
\text { cuidado }\end{array}$} & \multirow[t]{2}{*}{$\begin{array}{c}\text { Distancia } \\
\text { media } \\
(\mathrm{km})\end{array}$} & \multirow[t]{2}{*}{$\begin{array}{l}\text { Ayuda a } \\
\text { otros } \\
(\%)\end{array}$} & \multicolumn{3}{|c|}{$\begin{array}{c}\text { Edad de } \\
\text { los nietos } \\
(\%)\end{array}$} \\
\hline & & & & & & & 0-3 años & 4-10 años & >10 años \\
\hline Austria (639) & 35,68 & 3,67 & 14,24 & 451 & 4,58 & 7,04 & 20,97 & 31,46 & 53,83 \\
\hline Alemania (995) & 39,29 & 3,46 & 9,85 & 590 & 4,82 & 9,05 & 23,82 & 34,07 & 47,94 \\
\hline Suecia (1.483) & 42,95 & 5,16 & 8,16 & 495 & 5,33 & 15,44 & 29,60 & 30,88 & 48,55 \\
\hline Países Bajos (1.059) & 52,97 & 4,30 & 8,69 & 581 & 4,85 & 5,29 & 40,51 & 36,73 & 34,09 \\
\hline España (1.101) & 22,07 & 5,38 & 35,97 & 563 & 3,74 & 26,16 & 23,25 & 24,34 & 59,40 \\
\hline Italia (1.103) & 41,16 & 3,77 & 26,93 & 600 & 3,92 & 13,96 & 32,55 & 31,82 & 44,06 \\
\hline Francia (1.696) & 31,54 & 5,54 & 16,80 & 801 & 5,12 & 20,99 & 22,23 & 23,35 & 61,26 \\
\hline Dinamarca (1.139) & 52,06 & 4,25 & 5,09 & 822 & 5,35 & 6,67 & 36,79 & 37,84 & 36,61 \\
\hline Grecia (1.522) & 28,65 & 4,67 & 32,33 & 676 & 3,63 & 19,84 & 13,67 & 21,62 & 67,94 \\
\hline Suiza (722) & 33,80 & 5,01 & 12,46 & 484 & 4,81 & 16,76 & 22,44 & 25,07 & 58,17 \\
\hline Bélgica (1.355) & 47,68 & 4,15 & 13,06 & 1.076 & 4,53 & 7,90 & 27,97 & 32,47 & 47,82 \\
\hline Chequia (1.434) & 38,08 & 3,57 & 16,95 & 715 & 4,33 & 9,07 & 24,34 & 30,89 & 52,02 \\
\hline Polonia (1.606) & 37,80 & 5,75 & 47,07 & 724 & 3,78 & 23,16 & 27,15 & 37,17 & 46,64 \\
\hline Total (15.854) & 38,61 & 4,61 & 20,16 & 683 & 4,50 & 14,67 & 26,39 & 30,42 & 49,99 \\
\hline
\end{tabular}

Fuente: Elaboración propia a partir de la encuesta SHARE 2006. 
Las cifras mostradas en la Tabla 1 (primera columna) aparentemente contradicen el tópico acerca de la preocupación y el peso de la familia en los países mediterráneos. Sorprende encontrar que los Países Bajos cuentan con el mayor porcentaje de abuelos cuidadores (52,97\%), seguidos de Dinamarca (52,06\%). También sorprende la posición de España, que, con un $22,07 \%$ de abuelos cuidadores, es el país que menos cuidado ofrece por parte de los abuelos. La precede Grecia, con un $28,65 \%$ de hogares de abuelos con nietos a los que cuidan.

El número de nietos no ofrece una explicación a este patrón. Se podría esperar que, en los países con una media de nietos más alta, los hogares cuidadores de los abuelos serían también más, pero no es así. Un ejemplo de ello lo constituye, de nuevo, nuestro país, que siendo el segundo en número de nietos (con una media de 5,38), tras Polonia, presenta el porcentaje más bajo de abuelos cuidadores. 0 a la inversa, los Países Bajos, que, con un número medio de nietos inferior a la media total de los países analizados, es el que más abuelos cuidadores presenta.

El número medio de nietos tampoco responde al perfil esperado en los países mediterráneos, ya que encontramos países nórdicos, como Suecia, con 5,16 nietos de media, y otros mediterráneos, como Italia, con tan sólo 3,77. La convivencia entre abuelos y nietos se da en un $20,16 \%$ de los casos, pero es una situación más frecuente en el sur (incluida Polonia) que en los países del centro y norte de Europa. Polonia, con $47,07 \%$, es el país donde más frecuencia de convivencia se observa; España es el segundo, con $35,97 \%$; y Grecia e Italia muestran igualmente valores por encima de la media, con $32,33 \%$ y $26,93 \%$, respectivamente.

Las horas de cuidado ofrecidas por los abuelos muestran diferencias importantes entre los países. El país con mayor valor medio es Bélgica, con un total de 1.067 horas medias anuales. El número total de horas de cuidado se calcula a partir del tiempo que declaran los abuelos, a quienes no se les pregunta directamente por el total de horas anuales (que conduciría inexorablemente a errores de cómputo), sino por la frecuencia de cuidado de los nietos (diaria, semanal, mensual) y la duración del cuidado cada día, semana o mes. En algunos casos, los abuelos declaran un total de horas por meses 0 semanas que, agregadas, superan las horas que tiene un año (8.760). Ello puede explicarse porque ofrecen cuidado a varios nietos simultáneamente, de forma que si han cuidado durante la misma hora a dos nietos, imputan una hora para cada nieto, pudiendo resultar en un total de horas anuales superior a 8.760 , incluso en ausencia de convivencia de abuelos y nietos. Hemos censurado el total de horas al máximo anual, y con esas cifras se ofrecen las medias por países.
Una de las variables que se han tomado para explicar el cuidado de abuelos a nietos es la distancia entre unos y otros (Hank y Buber, [2007] utilizan la primera ola de los datos SHARE, referida al año 2004). Para incluir, como variable explicativa, la distancia a la que viven los abuelos de los nietos, se construye un indicador medio de distancia, a partir de la información categórica que muestra la encuesta SHARE, en la que el máximo valor (9) denota que la distancia entre abuelos y nietos es superior a 500 kilómetros, y el mínimo valor (1), implica que comparten hogar3.

La encuesta también informa acerca del cuidado ofrecido a otros miembros del hogar (nietos aparte). La media de hogares que ofrecen cuidado dentro del mismo hogar es de $14,67 \%$, siendo España el país donde esta circunstancia es más frecuente, con un $26,16 \%$ de media, seguido por Polonia (23,16\%), Francia (20,99\%), Grecia (19,84\%) e Italia (13,96\%). En esta circunstancia sí que se corrobora el perfil mediterráneo de cuidado en la familia.

\section{4. ¿Cuánto cuidan los abuelos a sus nietos en España?}

La intensidad con la que se da el cuidado de los abuelos hacia los nietos es fundamental para conocer la utilidad que se está produciendo por parte de cuidadores y receptores de cuidados. Si la sociedad está organizada de forma que los niños pueden ser atendidos por sus padres de manera regular, el cuidado de los abuelos se presentará de modo más voluntario. En cambio, cuando los hijos no cuentan con otra salida que pedir ayuda a los padres para cuidar de sus hijos, el cuidado se convierte en una 'responsabilidad laboral', en lugar de una actividad de disfrute, calificable como 'ocio'. Con los datos de los que se dispone, no es posible determinar el grado de voluntariedad con la que los abuelos atienden a los nietos, pero lo esperable es encontrar una relación negativa entre voluntariedad e intensidad, de manera que los abuelos que cuidan muchas horas a sus nietos, aunque lo hayan aceptado por los motivos que sea, se hayan visto forzados a ello, por constituir la única alternativa de ayuda para sus propios hijos, mientras que los que cuidan de forma más esporádica incorporen un componente más voluntario en el cuidado.

En el Gráfico 1 se presenta la distribución de frecuencias de las horas de cuidado de los nietos en el conjunto de países para los que la encuesta SHARE de 2006 presenta datos, incluyendo España, mientras que en el Gráfico 2 se muestra la misma distribución de frecuencias referida exclusivamente al caso español.

3 Un valor de 2 significa que viven en el mismo edificio; 3, a menos de $1 \mathrm{~km}$ de separación; 4, a entre 1 y $5 \mathrm{~km} ; 5$, a entre 5 y 25 km; 6, a entre 25 y $100 \mathrm{~km} ;$, a entre 100 y 500; 8, a más de 500 km; y 9, a más de 500 km y en otro país. 
№ de abuelos

153.555

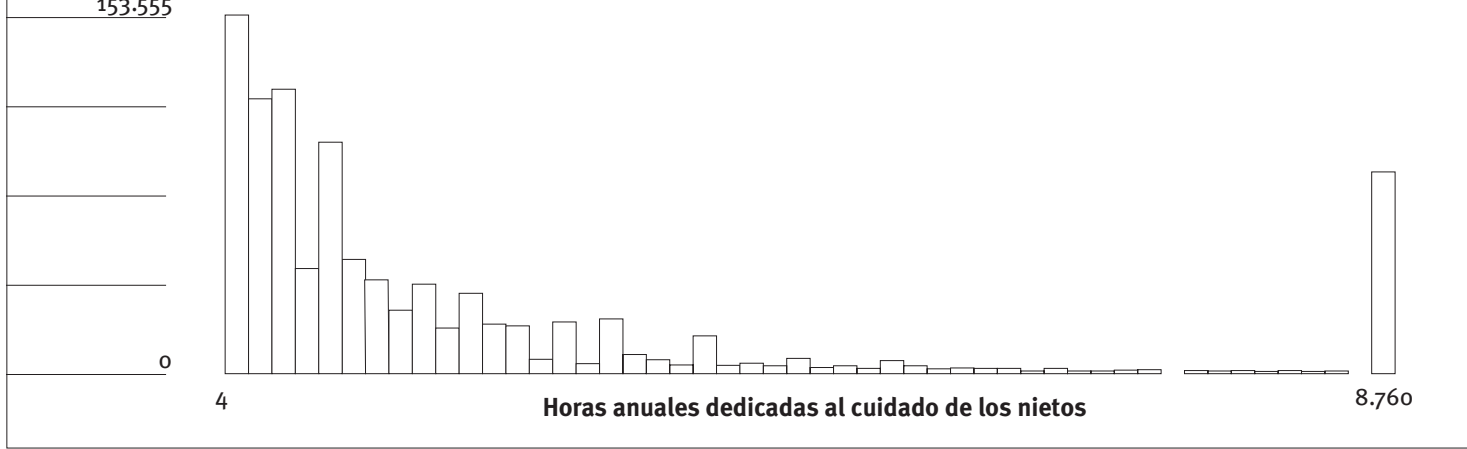

Fuente Elaboración propia a partir de la encuesta SHARE 2006.

Gráfico 2. Horas que los abuelos dedican al cuidado de los nietos. España, 2006

№ de abuelos

170.833

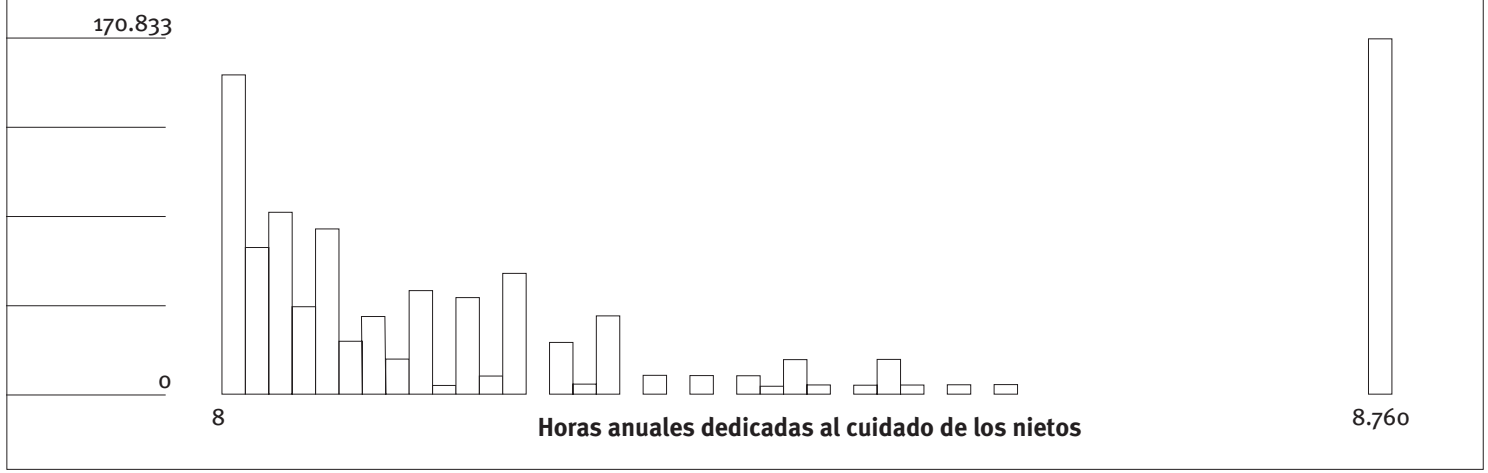

Fuente Elaboración propia a partir de la encuesta SHARE 2006.

A simple vista, la distribución de frecuencias ofrece un gráfico bastante similar, con frecuencias en descenso a medida que aumenta el número de horas de cuidado y con una gran acumulación de la frecuencia observada en el máximo censurado. Para todos aquellos abuelos que declaran un número de horas de cuidado superior a las horas del año, suponemos el máximo de 8.760 , que se presenta con una frecuencia en España del 17\%, mientras que para el conjunto de países europeos analizados se sitúa en torno al $10 \%$. Esta cifra presenta un primer indicio que apunta hacia un cuidado más intensivo en España que en el conjunto de los países europeos.

Un análisis más pormenorizado de la distribución de las horas de cuidado revela que existen diferencias notables entre los valores medios de horas de cuidado para diferentes percentiles.

Tabla 2. Horas anuales y diarias que dedican los abuelos al cuidado de los nietos* (datos en percentiles). Varios países europeos y España, 2006

\begin{tabular}{|c|c|c|c|c|c|c|}
\hline \multirow[t]{2}{*}{ Percentil } & \multicolumn{2}{|c|}{ Europa } & \multicolumn{4}{|c|}{ España } \\
\hline & h/año & h/día & h/año & h/día & No viven juntos & Viven juntos \\
\hline 1 & 12 & 0,0 & 12 & 0,0 & 16 & 8 \\
\hline 5 & 40 & 0,1 & 32 & 0,1 & 32 & 24 \\
\hline 10 & 96 & 0,3 & 96 & 0,3 & 80 & 108 \\
\hline 25 & 312 & 0,9 & 416 & 1,1 & 416 & 416 \\
\hline 50 & 8.32 & 2,3 & 1.248 & 3,4 & 1.095 & 1.460 \\
\hline 75 & 2.074 & 5,7 & 3.306 & 9,1 & 3.650 & 2.920 \\
\hline 90 & 5.200 & 14,2 & 8.760 & 24,0 & 8.760 & 8.760 \\
\hline 95 & 8.760 & 24,0 & 8.760 & 24,0 & 8.760 & 8.760 \\
\hline 99 & 8.760 & 24,0 & 8.760 & 24,0 & 8.760 & 8.760 \\
\hline Total & 1.785 & 4,9 & 2.603 & 7,1 & 2.693 & 2.452 \\
\hline
\end{tabular}

* Se ha considerado únicamente a los abuelos que declaran ocuparse de los nietos un número concreto de horas. Fuente: Elaboración propia a partir de la encuesta SHARE 2006. 
En la Tabla 2, se comparan los valores medios obtenidos para diferentes percentiles, ordenando de menor a mayor el número de horas dedicado al cuidado de los nietos y considerando exclusivamente los casos en que se declara un número concreto de horas. Se puede apreciar que, en España, la intensidad del cuidado es significativamente mayor que en el conjunto de países europeos analizado. Si bien el comportamiento en los percentiles más bajos es similar, e incluso presenta menor intensidad en España (por ejemplo, considerando el $5 \%$ que menos horas dedican al cuidado, el valor medio de horas declarado es de 32 en España, y 40 en Europa), ocurre que a medida que se hace más intenso el cuidado, las horas dedicadas en España aumentan considerablemente. Para que el total de horas anuales no impida comprender lo que esto significa, se han calculado las horas dedicadas cada día. En estos términos, los valores medios totales señalan una dedicación de 4,9 horas diarias de cuidado en el conjunto europeo, y de 7,1 horas diarias en el caso español. En el valor mediano, que divide a la población en dos mitades, los valores son 2,3 horas en Europa y 3,4 si se considera solamente España. Si ascendemos al percentil del $75 \%$ que más horas de cuidado dedican, las cifras señalan 5,7 horas diarias para Europa y 9,1 horas en España. Hay que tener en cuenta que las horas de cuidado diarias se han calculado incluyendo los fines de semana, que habitualmente no son laborables, por lo que la dedicación los días laborables puede ser incluso mayor ${ }^{4}$.

Los datos comparativos que ahora se ofrecen relativos al tiempo dedicado al cuidado de los nietos (7,1 horas medias diarias en España frente a 4,9 horas diarias de media europea) aparentemente contradicen los valores previamente calculados para los distintos países, que se presentaron en la Tabla 1. En ella se mostraba que la media de horas de cuidado en España (563 horas anuales, 0 1,5 diarias) era inferior a la europea (683 horas anuales, lo que significa 1,9 horas diarias), ya que tales datos estaban referidos al conjunto de abuelos que tienen nietos (los cuidasen o no). Teniendo en cuenta que el porcentaje de abuelos cuidadores en España es bastante menor que en el conjunto de países europeos analizados, es comprensible que la media de horas de cuidado entre los abuelos que sí que cuidan a sus nietos (22\% entre los que tienen nietos) sea mucho mayor en España.

Cabría pensar si la elevada intensidad declarada en el cuidado de los nietos en España es debida a que los nietos y los abuelos convivan en el mismo hogar. Por ello, la Tabla 2 también separa los valores por percentiles para abuelos que conviven y que no con-

${ }^{4}$ No se han excluido los fines de semana porque no es posible saber en qué momento de la semana se produce el cuidado por parte de los abuelos. viven con sus nietos. Contrariamente a lo que cabría esperar, los casos en los que se da la convivencia, arrojan una media de horas de cuidado menor que cuando la convivencia no se da, y este resultado se observa también en distintos percentiles. La intensidad del cuidado no parece deberse, entonces, a la ocasión que supone que los abuelos vivan en el hogar, ya que los que viven en otra vivienda cuidan más horas, en términos medios, a sus nietos. Esta situación también podría venir explicada por el hecho de que, cuando los abuelos comparten hogar con los nietos, los mayores presentan un nivel de dependencia mayor que los que viven de forma separada, y ese nivel de dependencia les podría incapacitar para hacerse cargo de los nietos. Con el fin de determinar si este tipo de circunstancias se da de manera concurrente, en los epígrafes posteriores describiremos el estado de salud de los abuelos cuidadores, así como su grado de autonomía, y se tratará de establecer causalidad entre las circunstancias que rodean a los abuelos, la probabilidad de cuidar nietos y la intensidad con que ejercen ese cuidado.

\section{5. ¿Cuál es el estado de salud y el nivel de autonomía de los mayores que cuidan nietos, frente a quienes no los cuidan?}

En el marco de la descripción de la situación en la que se encuentran los mayores encuestados, es interesante conocer si existen diferencias en el estado de salud, en las dolencias padecidas, o en la limitación presentada para desarrollar actividades, del colectivo que cuida nietos, frente al de quienes no los cuidan.

Los datos de SHARE 2006 recogen información muy detallada acerca del estado de salud de los encuestados, así como de las limitaciones que padecen para realizar actividades de la vida cotidiana. En este apartado presentamos algunas de las variables que captan la limitación y el estado de salud, según se trate de abuelos que cuidan nietos, o no. La selección no ha sido aleatoria: se han escogido aquellas variables de las que, a priori, cabía esperar un poder explicativo mayor, atendiendo a enfermedades o limitaciones que pueden llegar a dificultar en gran medida que un mayor se haga cargo de los nietos, como padecer Alzhéimer, sufrir la enfermedad de Parkinson o tener dificultad para orientarse en la calle, coger el teléfono o ducharse solo.

Es preciso recalcar el hecho de que la preparación de las variables para este estudio se ha realizado de forma que se capte la máxima información de los hogares. En realidad, no sabemos qué persona es la encargada directamente del cuidado de los nietos; por ello, se han utilizado variables que reflejan el hecho de que en el hogar exista al menos una persona con determinada dolencia, o con dificultad para 
realizar una tarea determinada. Ello no quiere decir que sea la persona con mayor dificultad la que se encargue de cuidar a los nietos; simplemente comprobamos que en los hogares donde se cuidan nietos (o no) se dan (o no) determinadas características en el conjunto de sus miembros.

Tabla 3. Abuelos cuidadores, en función de que se den en su hogar determinadas circunstancias de salud. España, $2006(\%)$

\begin{tabular}{l|l|l|l|l|}
\hline Circunstancia & Alzhéimer Parkinson & Depresión & Mejor & Duerme
\end{tabular}

\begin{tabular}{l|c|c|c|c|c} 
& & & & $\begin{array}{c}\text { Mejor } \\
\text { morir }\end{array}$ & $\begin{array}{c}\text { Duerme } \\
\text { mal }\end{array}$ \\
\hline No & 19,17 & 18,62 & 14,84 & 17,97 & 15,77 \\
\hline Sí & 11,63 & 21,43 & 19,86 & 20,63 & 19,75 \\
\hline
\end{tabular}

Fuente: Elaboración propia.

Tabla 4. Abuelos cuidadores, en función de que se den en su hogar determinadas circunstancias de salud. España, 2006 (\%)

Dificultad Cocinar Manejar Ducharse Orientarse Manejar Vestirse

\begin{tabular}{|c|c|c|c|c|c|c|}
\hline & & dinero & & & teléfono & \\
\hline No & 19,94 & 19,19 & 20,34 & 19,36 & 19,44 & 19,26 \\
\hline Sí & 12,66 & 16,46 & 14,32 & 17,19 & 13,71 & 17,2 \\
\hline
\end{tabular}

Fuente: Elaboración propia.

Tabla 5. Incidencia de determinadas circunstancias de salud, en función de si en el hogar los abuelos cuidan o no a sus nietos. España, 2006 (\%)

\begin{tabular}{l|l|l|l|l|l|l|}
\hline Cuidan & Alzhéimer & Parkinson & Depresión & Mejor & Duerme & Limitación
\end{tabular}

\begin{tabular}{l|c|c|c|c|c|c} 
nietos & & & & morir & mal & media \\
\hline No & 7,09 & 2,05 & 37,53 & 25,86 & 72,08 & 2,46 \\
\hline Si & 4,06 & 2,44 & 45,53 & 29,87 & 77,23 & 2,46 \\
\hline
\end{tabular}

\begin{tabular}{l|l|l|l|l|l|l}
\hline Sí & 4,06 & 2,44 & 45,53 & 29,87 & 77,23 & 2,46 \\
\hline
\end{tabular}

Fuente: Elaboración propia.

Tabla 6. Incidencia de determinadas dificultades, en función de si en el hogar los abuelos cuidan o no a sus nietos.

España, 2006 (\%)

\begin{tabular}{l|c|c|c|c|c|c}
\hline $\begin{array}{l}\text { Cuidan } \\
\text { nietos }\end{array}$ & Cocinar & $\begin{array}{c}\text { Manejar } \\
\text { dinero }\end{array}$ & Ducharse & Orientarse & $\begin{array}{c}\text { Manejar } \\
\text { teléfono }\end{array}$ & Vestirse \\
\hline No & 18,67 & 19,42 & 25,30 & 31,93 & 14,10 & 28,76 \\
\hline Sí & 11,79 & 16,66 & 17,07 & 28,86 & 9,76 & 26,02 \\
\hline
\end{tabular}

Fuente: Elaboración propia.

En las Tablas 3 y 4 se resumen, a partir de los valores medios, las diferencias entre la concurrencia de determinadas circunstancias para los grupos de abuelos que cuidan nietos y para los que no lo hacen. La interpretación de la Tabla 3 es la siguiente: separando el colectivo de encuestados según exista, o no, en el hogar una persona, al menos, que padece la enfermedad de Alzheimer, los porcentajes de cuidado de nietos entre los dos grupos son de $19,17 \%$ de abuelos cuidadores en el grupo de quienes no padecen la enfermedad, frente a $11,63 \%$ en los hogares en los que existe al menos una persona que la padece. Es decir, entre los hogares en los que se padece Alzhéimer, el cuidado de nietos se presenta con menor incidencia. Al contrario ocurre cuando se analiza la incidencia entre los hogares en los que hay algún enfermo de Parkinson: cuando se da tal circunstancia, la proporción de abuelos que cuidan nietos es de $21,43 \%$, frente al $18,62 \%$ cuando no se padece la enfermedad. Existe también una diferencia notable entre los hogares en los que al menos una persona se encuentra deprimida, donde hay más abuelos cuidadores (19,86\%) que en los hogares donde nadie padece depresión (14,84\%). Entre los hogares en los que alguien ha considerado que la vida no tiene sentido, la proporción de abuelos cuidadores es mayor que cuando tal circunstancia no se da, como muestran los porcentajes de $20,63 \%$ y $17,97 \%$, respectivamente. Por último, existen mayor proporción de abuelos cuidadores entre los que declaran que se duerme mal (19,75\%) que en los que dicen que se duerme bien (15,77\%).

Este mismo esquema es el que se recoge en la Tabla 4, esta vez para explicar el porcentaje de abuelos cuidadores entre el grupo de los que presentan, o no, determinada dificultad. Para todas las dificultades consideradas, se comprueba que los porcentajes de abuelos cuidadores descienden siempre que se sufre de alguna dificultad. El caso más obvio aparece cuando se considera la dificultad para ducharse: el porcentaje de cuidadores entre los que no se sufre tal circunstancia es del 20,34\%, y desciende a $14,32 \%$ cuando la dificultad aparece. También la dificultad para cocinar abre una divergencia importante entre los porcentajes de cuidado: $19,94 \%$ cuando no existe esa dificultad, y solamente $12,66 \%$ cuando esa dificultad se da.

Las Tablas 5 y 6 explotan la misma información, pero de forma inversa. Lo que ahora se presentan son los porcentajes de incidencia de determinadas dolencias o limitaciones para el conjunto de hogares en los que se cuidan, o no, a los nietos. Por ejemplo, ¿en qué porcentaje de hogares hay, al menos, un enfermo de Alzhéimer entre los que cuidan nietos, frente a los hogares en los que no se cuida a los nietos? La respuesta es 7,09\% entre los hogares en los que no se cuida a los nietos, frente a $4,06 \%$ entre los hogares de cuidadores. Las conclusiones obtenidas son las mismas que se han reseñado en las Tablas 3 y 4 , pero en este caso se comprueba la incidencia diferenciada de las distintas circunstancias. Es interesante comprobar que en un $45,53 \%$ de los hogares en los que se cuida a nietos hay al menos alguien que se siente deprimido (frente al 37,53\% de incidencia de depresión entre los no cuidadores), o que en el $29,87 \%$ de los hogares en los que se cuida a los nietos se ha pensado en acabar con la vida (frente a un $25,86 \%$ de incidencia de esta idea en los hogares en los que no se ofrece cuidado a nietos). También entre los hogares de cuidadores se duerme peor que en los que no se cuida a los nietos $-77,23 \%$ de hogares en los que se declara que se duerme mal, frente al $72,08 \%$ entre los hogares no cuidadores-. Es sorprendente la coincidencia de los niveles de limitación declarados en los dos grupos. Si el valor 1 representa la situación de limitación 
más severa, y 3, la de ausencia de limitación, el valor medio de limitación en los hogares en los que se cuida a nietos, o no, es 2,46 en todo caso.

La Tabla 6 pone de manifiesto que, en los hogares en los que se cuida a los nietos, las dificultades para realizar determinadas tareas, como cocinar, manejar dinero, ducharse, orientarse, utilizar el teléfono o vestirse, siempre están menos presentes que en los hogares en los que no se cuida a los nietos.

Una conclusión derivada de los datos que se han detallado en este apartado es que la concurrencia de determinadas enfermedades o sentimientos de depresión no necesariamente rebaja la incidencia del cuidado de los nietos por parte de los abuelos. En cambio, cuando se trata de dificultades físicas para realizar tareas, se comprueba que, en los casos en los que la dificultad se presenta, la incidencia del cuidado es siempre menor.

Aunque no se trate de dificultad para realizar tareas, se ha considerado relevante determinar el porcentaje de hogares en los que se cuida a los nietos atendiendo a las dificultades económicas que se declaran para terminar el mes. Se ha comprobado que los hogares en los que se reconocen dificultades en este sentido, la incidencia del cuidado se da por encima de la media, y de forma mucho más intensa en los hogares que manifiestan gran dificultad. Así, si el porcentaje de abuelos cuidadores entre los que contestan a la pregunta de la dificultad con la que llegan a final de mes es de $20,02 \%$, ese porcentaje se eleva hasta $28,49 \%$ en los hogares que padecen mayor dificultad económica. Los hogares que declaran llegar fácilmente a final de mes presentan un porcentaje de cuidadores del $16,39 \%$. También es cierto que existen ciertas discontinuidades y que no es posible señalar una relación estrictamente creciente entre la incidencia del cuidado y la dificultad económica.

Sería interesante conocer cuál es la situación económica de los padres en lugar de los abuelos, que posiblemente tendría un poder explicativo mayor, pero los datos SHARE tienen como objeto la caracterización de los hogares de los mayores y no de los jóvenes, por lo que no se cuenta con tal información.

\section{6. ¿Qué características hacen más probable convertirse en abuelo cuidador en España?}

Los datos SHARE de 2006 referidos España permiten comprobar que, entre los 1.317 hogares de la encuesta, un $81 \%$ no cuida a los nietos, frente a un $19 \%$ que sí lo hace. Pero muchos de los abuelos que no cuidan a nietos no lo hacen, simplemente, porque no tienen nietos, por ello, el porcentaje relevante es el derivado del colectivo que sí tiene nietos. En este caso, y con un conjunto de observaciones de 1.101 hogares, el $22 \%$ declara que cuida a sus nietos en ausencia de sus padres, frente al $78 \%$ restante que no lo hace.

En el presente apartado presentamos las conclusiones obtenidas al aislar las características que determinan la probabilidad de que en un hogar se dé la característica de cuidador de nietos, mediante un modelo probit de elección discreta. Los detalles del modelo se pueden ver en Badenes y López (2009). Una novedad del estudio frente a trabajos similares, como el de Hank y Buber (2007), es considerar las características medias del hogar, en lugar de fijarse exclusivamente en las características del abuelo o la abuela cuidadores. La justificación para adoptar este enfoque es que consideramos el hogar como unidad de decisión, y el cuidado de los nietos implica, de alguna forma, a todos los miembros del hogar, no exclusivamente a los abuelos, por lo que las características de los restantes miembros pueden ser también relevantes para explicar el cuidado.

Las variables que han resultado tener poder explicativo para explicar el fenómeno del cuidado por parte de los abuelos, así como la forma en la que influyen en la probabilidad de ser abuelo cuidador, se detallan a continuación:

- Cuando los mayores viven solos en el hogar, es menos probable que cuiden a sus nietos que cuando están integrados en una unidad familiar, o al menos comparten la vivienda con alguien más.

- Los mayores que brindan su ayuda a otras personas diferentes de los nietos -sean o no de la familia- cuidan a sus nietos con mayor probabilidad.

- Cuando en un hogar de mayores al menos una persona declara dificultad para ducharse solo, es menos probable que se cuide a los nietos que cuando tal dificultad no existe.

- En los hogares en los que algún miembro se siente deprimido, es más probable que se esté cuidando a los nietos.

- La dificultad económica para terminar el mes no influye en la probabilidad de que los mayores cuiden a los nietos.

- La edad de los nietos es una variable que tiene gran poder explicativo en la probabilidad del cuidado por parte de los abuelos. Así, los abuelos que tienen al menos un nieto en el tramo de edad de o a 3 años tienen mucha más probabilidad de ser cuidadores que los que no cuentan con nietos de esas edad. Al contrario, cuando los abuelos cuentan con algún nieto en el tramo de edad de 10 o más años, la probabilidad de ser cuidadores desciende de forma muy significativa. 
- El número total de hijos varones y de hijas mujeres no es significativo en la explicación de la probabilidad del cuidado por parte de los abuelos.

- La distancia media a la que viven los nietos no es significativa, aunque presenta el signo esperado: negativo.

- Cuanto mayor es la proporción de hijos que viven con pareja, mayor es la probabilidad de convertirse en abuelo cuidador.

- Cuanto mayor es la autonomía laboral de los hijos, menor es la probabilidad de que los abuelos cuiden a sus nietos.

Los resultados anteriores son meras comprobaciones econométricas referentes a la significatividad de los parámetros del modelo. Veamos ahora qué realidad puede estar subyaciendo tras las conclusiones anteriores.

El hecho de que los abuelos solos cuiden menos a sus nietos puede estar generando un círculo vicioso de soledad: los abuelos que no conviven con otros adultos están también más solos en los que se refiere a compartir el tiempo con sus nietos. También puede interpretarse como una situación de dificultad para hacerse cargo de responsabilidades: las personas mayores que no conviven con otra persona consideran que, por sí solas, es más difícil hacerse cargo de los nietos, y asumen en menor medida esta responsabilidad que los abuelos que no viven solos.

Se ha constatado que quienes cuidan a otras personas, cuidan a los nietos con mayor probabilidad. Este efecto podría expresar el carácter altruista de determinados hogares, en los que se ayuda a quien lo necesita, sean menores o mayores.

El efecto de la dificultad para ducharse sólo puede reflejar una dificultad de movimientos más general y la tendencia a la falta de autonomía de muchos mayores. Aunque se ha comprobado cómo influye la presencia de dificultades para realizar otras tareas, como cocinar, utilizar el teléfono u orientarse, solamente la dificultad para ducharse es significativa. Obviamente, aquellas personas menos autónomas, o con mayor dificultad de movilidad, tienen también menor capacidad para hacerse cargo del cuidado de los nietos. Al mismo tiempo, cuando en el hogar reside una persona con dificultad de movimientos, el resto de miembros pueden estar más involucrados en su cuidado y estar menos disponibles para cuidar a los nietos. Es decir, que los problemas de movilidad en el hogar pueden hacer descender la probabilidad del cuidado de los nietos tanto por menor disponibilidad de dar cuidado por parte de los mayores como por mayor necesidad de percibir esos cuidados los mismos mayores, de manera que abuelos y nietos se convierten en sustitutos en la percepción de los cuidados.
La correlación positiva entre los sentimientos de depresión de algún miembro del hogar y el cuidado de los nietos puede interpretarse en sentido bidireccional. ¿Se deprimen los abuelos porque cuidan a sus nietos, o los cuidan porque se sienten deprimidos? La cuestión no es tan sencilla, pero esta correlación pone de manifiesto que existen hogares en los que los mayores se sienten deprimidos y, sin embargo, se hacen cargo de niños. Si el cuidado se produce de forma esporádica o no muy intensiva, el cuidado de los niños puede representar un alivio para los que se sienten deprimidos. Cuando el cuidado se produce de modo muy intensivo, como es frecuente en nuestro país, la combinación de un adulto deprimido y una presencia continua de niños en el hogar puede empeorar la situación tanto del adulto como de los niños. Del adulto, por el estrés al que puede verse sometido por una carga de trabajo importante derivada del cuidado intensivo de los menores, y del menor, por el ambiente percibido en el hogar del cuidador.

Se ha constatado el carácter no significativo de la dificultad declarada por los encuestados para terminar el mes. Esta variable se introdujo como una proxy del nivel económico del hogar de los abuelos, para poder determinar si los abuelos con más solvencia financiera cuidaban más a los nietos, o lo hacían más aquellos con mayores dificultades económicas. Parece, entonces, que el fenómeno del cuidado no depende de la capacidad económica que tengan los abuelos. Aunque no se ha presentado en el modelo por su escasa significatividad, también se comprobó el efecto de la edad de los abuelos, pues cabía esperar un descenso en la probabilidad de cuidado a medida que los abuelos envejecen. Este efecto no se ha podido constatar ni con la edad media del hogar, ni con la presencia de biznietos, ni con la edad media de los hijos, variables estas últimas correlacionadas positivamente con la edad de los abuelos. Nuestra conclusión al respecto es que el cuidado de los nietos viene motivado por otras variables que dependen más de la necesidad de los hijos y la disponibilidad de los abuelos, pero que no tienen tanto que ver con la edad de éstos. Es decir, si los hijos necesitan acudir a los abuelos para que les ayuden el cuidado de los niños, lo harán siempre que los abuelos se muestren disponibles, y eso lo determina básicamente la voluntad, su estado de salud físico y mental, pero no la edad que tengan. Es cierto que la edad y la mala salud se correlacionan positivamente, pero controlando por estado de salud, la edad no tiene, por sí misma, poder explicativo en la capacidad de cuidar a los nietos.

El efecto gradiente según la edad de los nietos que se ha constatado para el caso español también se ha encontrado para otros países (Badenes y López, 2009; Hank y Buber, 2007). La interpretación de lo obtenido es que los abuelos cuidan más de los nietos pequeños que de los mayores. Si hubiésemos 
desagregado más por niveles de edad, posiblemente se habría comprobado que los niños menores de un año constituyen una excepción, ya que requieren mayor presencia de la madre y cuidados menos sustituibles (Hank y Buber, 2007); pero lo que es cierto es que los nietos más pequeños son más cuidados por los abuelos que los mayores. En el caso de edades superiores a los diez años, el efecto es el contrario: la probabilidad de cuidar a los nietos cuando se cuenta con nietos mayores desciende de forma muy significativa. Ello viene explicado por la mayor autonomía de los niños a partir de los diez años, quienes pueden, incluso, permanecer solos en el hogar sin la presencia de los padres, o trasladarse por sí mismos al centro escolar sin el acompañamiento de un adulto. Esta situación denota que el cuidado de los abuelos es entendido más como una ayuda a la conciliación de la vida laboral y familiar de los hijos que como un cuidado destinado a la educación de los nietos. Si fuese de esta forma, los abuelos mantendrían la probabilidad de ser cuidadores incluso cuando no fuese necesario ayudar a la conciliación.

\section{La autonomía laboral}

media de los hijos

\section{es determinante en la explicación de}

\section{la probabilidad del cuidado de los nietos}

La razón para introducir por separado a los hijos varones y las hijas mujeres es que, cuando se ha analizado el cuidado de nietos por parte de los abuelos en el conjunto de países europeos (Badenes y López, 2009), se ha encontrado mayor inclinación hacia el cuidado cuando los nietos son descendientes de hijas y no de nueras (o menor cuidado ante los descendientes de hijos frente a yernos). Este efecto no es significativo para España, si bien se comprueba que el signo del coeficiente es positivo para el total de hijas, y negativo para el de hijos. También se ha comprobado si el total de hijos (varones o mujeres) incide sobre la probabilidad de cuidado de los abuelos, esperando obtener un signo positivo, ya que tener más hijos implica mayor probabilidad de tener nietos, y por tanto, de convertirse en cuidador de alguno de ellos, pero el resultado ha sido de ausencia de significatividad. Una posible explicación es el sentimiento de justicia de los abuelos, o de conciencia de sobrecarga de los hijos. Cuando en una familia hay un número mayor de hijos, debería existir mayor probabilidad de ser un abuelo cuidador, porque también es más probable que haya más nietos. Si ante un mayor número de hijos no se observa mayor probabilidad de cuidado, puede ser porque, ante la cantidad de nietos potenciales receptores de cuidado, si no se puede atender a todos, los abuelos prefieren no discriminar entre ellos. Esta razón implicaría una ausencia de oferta de cuidado por parte de los abuelos. También puede aparecer una ausencia de demanda de cuidado por parte de los padres de los niños perceptores de cuidados, conscientes de la sobrecarga que pueden causar a sus padres, los posibles abuelos cuidadores.

La distancia media a la que viven los nietos de los abuelos no es significativa en el caso de España, si bien presenta el signo esperado, que indicaría que cuanto más lejos viven los abuelos y los nietos, menor es la probabilidad de ser abuelo cuidador. Esta ausencia de significatividad indica que no es la distancia lo que determina el cuidado por parte de los abuelos, sino otras características.

Existe un efecto muy significativo de la situación de pareja de los hijos sobre la probabilidad de que los abuelos cuiden a los nietos. Cuanto mayor es la proporción de hijos con pareja, mayor es la probabilidad de que se cuide a los nietos. Esto puede explicarse desde dos puntos de vista alternativos. Por un lado, entre todos los hijos puede haber algunos que tengan hijos, o no. Si los hijos están emparejados, es más probable que tengan hijos a su vez, y que los abuelos los cuiden; por ello, mayor proporción de hijos emparejados hace aumentar la probabilidad de cuidado. Pero esta explicación no es válida en nuestro caso, porque el estado de pareja se refiere a los hijos que, a su vez, tienen hijos. Si se trata, entonces, de hijos que no tienen pareja, pero tienen hijos a su vez, nos encontraríamos ante hijos más autónomos y que se hacen cargo ellos mismos de sus hijos con más probabilidad. Aquí también puede estar captándose el fenómeno de separación de abuelos y nietos cuando se da una ruptura en la relación de los hijos. Ello explicaría también el signo negativo del parámetro: los abuelos que tienen más hijos separados cuidan menos de sus nietos.

La autonomía laboral de los hijos se capta con un indicador que implica mínima autonomía cuando los hijos trabajan a tiempo completo, mayor si trabajan a tiempo parcial, mayor si están autoempleados o trabajan para la familia, y máxima en otra circunstancia. Se ha corroborado que la autonomía laboral media de los hijos es determinante en la explicación de la probabilidad del cuidado de los nietos. Ello reflejaría que los abuelos cuidan más a los nietos cuanto más lo necesitan los hijos, denotando en esta actitud un carácter altruista y protector hacia hijos y nietos, y de ausencia de verdadera voluntariedad. Serían, pues, las razones de demanda las que determinarían que los abuelos se conviertan en cuidadores. Los abuelos no cuidan a sus nietos cuando sus padres pueden hacerlo, lo hacen cuando la autonomía laboral de los padres les impide hacerse cargo ellos mismos. 
Otro conjunto de variables que se incluyó inicialmente en el modelo fue el estado de salud de los mayores, tanto el que declaran los propios encuestados -que presenta un componente subjetivocomo el que relativo a la existencia de dolencias específicas -cáncer, Alzhéimer, ataque al corazón-, pero cuyo padecimiento no presenta poder explicativo respecto a ser abuelo cuidador.

\section{7. ¿Qué características determinan que el cuidado de los nietos se haga de forma más intensiva en España?}

El epígrafe anterior se ha dedicado a explicar el hecho de que los abuelos cuiden o no a sus nietos, pero también resulta interesante averiguar cuáles son los determinantes de que el cuidado se realice $o$ no, y, cuando se da, que se haga de forma más o menos intensa. Se han ensayado varios modelos explicativos del número de horas dedicadas al cuidado de nietos, desde un modelo de regresión lineal de explicación de las horas para aquellos que declaran un número de horas positivas, hasta un modelo de selección de Heckman, en el que se explican simultáneamente la decisión de cuidar o no a los nietos, y, condicionados a la decisión de cuidarlos, los determinantes de las horas que dedican a su cuidado. No obstante, el mejor ajuste se ha logrado para un modelo de elección discreta similar al anterior. Se ha optado por utilizar un modelo probit ordenado o probit multinomial, en el que se modeliza la información discreta y ordenada a través de un índice inobservable. Las principales conclusiones obtenidas se detallan a continuación:

- Cuando en el hogar de los mayores alguna persona presenta dificultad para ducharse por sí mismo, la probabilidad de cuidar a los nietos durante más horas desciende.

- Si en el hogar las personas declaran dificultad para vestirse, la probabilidad de cuidar nietos durante más horas aumenta. Sin embargo, el coeficiente de esta variable es prácticamente la mitad que el obtenido para los hogares en los que se presenta dificultad para ducharse.

- El hecho de que algún miembro del hogar de los mayores se sienta deprimido está correlacionado positivamente con que se ofrezca un número mayor de horas de cuidado a los nietos.

- Tener un nieto en el rango de edad de o a 3 años se correlaciona positivamente con más horas de cuidado, mientras que si la franja de edad es de 10 o más años, la correlación entre ambas variables es negativa.

- La distancia que separa a nietos y abuelos presenta capacidad para explicar las horas de cuidado, de forma que cuanto mayor es la distancia, menor es el número de horas de cuidado.
- La situación de pareja de los hijos también explica las horas de cuidado, de modo que cuanto mayor es la proporción de hijos con pareja de entre los que tienen hijos, mayor es la intensidad del cuidado por parte de los abuelos.

- La independencia en términos laborales no tiene poder explicativo sobre las horas de cuidado.

- El hecho de haber sufrido un ataque al corazón no tiene poder explicativo sobre las horas de cuidado de los nietos.

- El estado de salud declarado por el encuestado del hogar (no el estado medio de salud del hogar) influye de manera que cuanto peor declara encontrarse un mayor, mayor es el número de horas de cuidado.

- El número de personas enfermas en el hogar de los mayores y el número de parados se relacionan negativamente con las horas de cuidado.

- El número total de hijos varones incide negativamente sobre las horas de cuidado.

En las siguientes líneas tratamos de profundizar algo más en lo que subyace a los signos de los coeficientes obtenidos en la estimación econométrica, así como en su posible interpretación y coherencia.

Uno de los intereses primordiales del presente estudio reside en determinar las circunstancias en las que se presta el cuidado de los abuelos hacia los nietos. Particularmente, es interesante saber si los abuelos que más cuidan a sus nietos presentan buen estado de salud física y mental, y si son autónomos al realizar distintas actividades, lo que redundará en su situación de dependencia. Con esta idea, en los modelos (probit y probit multinomial) se han diseñado alternativas en las que se incluían variables que captaban esta condición por parte de los abuelos. Si recordamos los resultados del modelo probit en el que se consideraban exclusivamente los determinantes de ser o no ser abuelo cuidador, parece que únicamente la limitación que supone no poder ducharse presenta poder explicativo. Con ello, concluíamos que solamente ante una limitación considerable -como no poder ducharse solo- disminuye la probabilidad de que los abuelos cuiden a sus nietos, ya que otro tipo de dificultades (para cocinar, manejar el teléfono u orientarse) no resultaron significativas en la explicación. En cuanto a salud mental, se observaba correlación positiva entre la existencia de sentimientos de depresión en el hogar de los cuidadores y cuidar a los nietos. Cuando se trata de explicar la intensidad del cuidado, de nuevo estas dos variables muestran un gran poder explicativo, y el signo es el mismo que en el modelo probit. Por ello, se puede concluir que la dificultad para ducharse (o bañarse solo) marca un descenso tanto en la probabilidad de cuidar a los nietos como en 
las horas de cuidado, y la depresión en el hogar del cuidador de nietos implica un aumento en la probabilidad tanto de ser cuidador como en las horas de cuidado.

Otras variables relacionadas con el estado de salud y la autonomía de los mayores que han resultado significativas son el estado de salud declarado por el encuestado, la dificultad para vestirse y el número de personas enfermas en el hogar de los mayores.

El modelo señala que cuando el encuestado declara encontrarse peor, las horas que se cuida a los nietos son mayores que cuando la salud es mejor. De nuevo nos planteamos cuál es el origen de la situación: si abuelos que declaran encontrarse mal cuidan más intensamente a sus nietos, entonces, ¿es que encontrándose mal, sus hijos necesitan de su ayuda, ignoran su estado de salud y dejan a su cuidado a los nietos?, ¿o es que el cuidado de los nietos genera un desgaste a los abuelos que les hace declarar un peor estado de salud? Sea cual fuere el origen, el hecho es que las circunstancias concurren: mala salud declarada por los abuelos y un cuidado más intensivo de los nietos.

En cuanto a la dificultad de los abuelos para vestirse $^{5}$, a priori se esperaba un signo negativo del coeficiente, de manera que fueran los abuelos con mayor limitación los que menor intensidad de cuidado presentaran. El hecho de encontrar una correlación positiva vuelve a plantear la cuestión anterior: si el desgaste de los abuelos se sufría antes y a pesar de ello los nietos están a su cargo, o si es el cuidado lo que les está desgastando.

El número de personas enfermas en el hogar incide negativamente sobre las horas de cuidado que ofrecen los mayores a sus nietos, lo cual es comprensible tanto porque los propios enfermos tienen menor capacidad para cuidar a los nietos como por el hecho de que personas mayores enfermas pueden ser receptoras de cuidados y limitan las oportunidades de los abuelos sanos para ofrecerse a cuidar a los nietos durante más tiempo.

Los rangos de edad de los nietos son determinantes en la explicación de las horas de cuidado: los menores de tres años parecen absorber más tiempo de cuidado, mientras que los mayores de diez implican un cuidado menos intensivo. Este resultado es el mismo que el obtenido cuando se explicó exclusivamente la probabilidad de ser abuelo cui-

\footnotetext{
${ }^{5}$ En cualquier caso, consideramos que esta limitación implica menor gravedad que para ducharse o bañarse, ya que en la pregunta sobre la dificultad para vestirse se incluye ponerse calcetines y abrocharse los zapatos, cosa que puede costar cierto esfuerzo en muchos mayores, sin llegar a impedir que puedan ducharse 0 bañarse solos.
}

dador. También se da coincidencia -como era esperable- en el efecto de la situación de pareja de los hijos que tienen hijos: cuanto mayor es la proporción de hijos con descendencia que tienen pareja, mayor es el número de horas de cuidado por parte de los abuelos. Este resultado contradice la evidencia de que las familias monoparentales precisan más del apoyo informal de los abuelos. Una explicación posible para tal efecto es que, en las familias en las que ha habido ruptura en la relación de pareja y han derivado en monoparentales, puede haberse extendido la ruptura a la relación con la generación anterior, que sería el caso de los abuelos separados de sus nietos por el divorcio de los hijos. En estos casos, que los nietos sean descendientes de hijos varones o de hijas mujeres es importante, ya que normalmente son las madres, y no los padres, quienes constituyen familias monoparentales en España, y son los nietos de hijo (y no de hija) quienes con mayor probabilidad pueden verse separados de los abuelos. Es cierto que no estamos considerando las 'horas que los abuelos pasan con sus nietos', sino las 'horas que los abuelos cuidan a sus nietos sin que sus padres estén presentes', pero la separación de abuelos y nietos en tales circunstancias se produce tanto para las visitas como para el cuidado.

El sexo de los hijos (cuyos hijos cuidan los abuelos) se ha considerado como variable explicativa de las horas de cuidado, y se ha obtenido lo esperado: el mayor número de hijos varones implica una menor cantidad de horas de cuidado de forma significativa. El signo ligado al total de hijas mujeres es positivo al explicar el número de horas, si bien no es significativo.

Al contrario de lo que ocurría en el modelo probit, la explicación de las horas sí que viene determinada por la distancia a la que viven abuelos y nietos. Por tanto, vivir lejos no es un impedimento para convertirse en cuidador, pero los abuelos que están más lejos cuidan menos horas de sus nietos. Esto indicaría que la necesidad de que los abuelos se encarguen de los nietos hace que se salven las distancias entre las residencias de unos y otros, pero que, por otro lado, cuando los abuelos viven cerca, sea más fácil que pasen más horas al cuidado de los nietos.

En la variable que recoge la independencia laboral de los hijos, también se observan diferencias en la significatividad hallada en el modelo probit y en el probit multinomial. Esta circunstancia es explicativa de la probabilidad de ser abuelo cuidador, pero no del número de horas de cuidado. Así, la mayor independencia laboral de los hijos explica que haya menos abuelos cuidadores, pero no se observan más o menos horas de cuidado según los hijos estén más o menos disponibles por motivos laborales. 


\section{Propuestas de actuación}

La dependencia no es un fenómeno novedoso: siempre ha habido personas a las que ha sido necesario atender y cuidar de una manera especial, por su edad, salud física o psíquica, o porque sus recursos eran escasos. Sin embargo, lo que se presenta como un nuevo reto para la sociedad actual es la forma de abordar y prestar estos cuidados. Hasta hace relativamente poco tiempo, la familia era la única responsable de atender a estas personas dependientes, $y$ se organizaba de forma que uno de sus miembros, normalmente la mujer, se ocupaba del cuidado y la atención de todos aquellos que la formaban, incluidos los dependientes. Si necesitaba ayuda, la solicitaba a otros miembros de la familia extensa, e incluso a sus vecinos. Los cambios sociales, entre ellos, la entrada de la mujer en el mercado laboral remunerado, el menor tamaño de las familias, el aumento en la esperanza de vida, y otros cambios en los comportamientos familiares, son fenómenos que han dado lugar a nuevas necesidades.

Muchas familias españolas manifiestan, en encuestas de naturaleza muy diferente, su deseo de atender a sus hijos y a sus mayores, a la vez que declaran que no disponen de recursos suficientes y que se encuentran con numerosos obstáculos para ello. Pero podemos hacer dos consideraciones a lo anterior. La primera es que, cuando hacen referencia a la falta de recursos, no se refieren exclusivamente a medios económicos sino, sobre todo, a tiempo y a falta de medios materiales, como viviendas adecuadas o servicios de atención y apoyo domiciliario. Y en segundo lugar, y en relación a la existencia de obstáculos, consideran que los más importantes surgen cuando se trata de conciliar la vida familiar y laboral: horarios muy extensos y rígidos, falta de coordinación entre los horarios escolares y laborales, vacaciones escolares y laborales descoordinadas o dificultades a la hora de cuidar a los mayores en el propio domicilio familiar.

Las nuevas formas de vida de las familias más jóvenes han traído la aparición del fenómeno que se viene analizando en este trabajo: el nuevo papel de los abuelos en el cuidado familiar. Se trata de un fenómeno que presenta una doble cara. Personas mayores, potencialmente dependientes e incluso, en algún caso y en cierta medida, dependientes reales, que, por diversas circunstancias, se ven obligadas, desde el amor, el cariño y la generosidad, a cuidar de sus nietos cuando sus padres no pueden hacerlo. Estos abuelos deben ser considerados como un colectivo preferente a la hora de hablar de dependencia. El principal motivo está en el hecho de que la actuación que debe ser prioritaria respecto al fenómeno de la dependencia es su prevención. Esto exige ayudar a los padres a eliminar los obstáculos que les impiden cuidar de sus hijos, para que los abuelos puedan cuidar a sus nietos cuando esto sea necesario, pero que no se vean obligados a adoptar el papel de padres, que no les corresponde.

Debemos ser cuidadosos al tratar de apoyar al colectivo de abuelos que atienden a sus nietos, ya que esta actividad puede constituir una ayuda a los abuelos para envejecer y pasar esta etapa de su vida con mayor alegría y en compañía. Pero también puede ser, como ha quedado patente en el análisis del SHARE, una responsabilidad que les puede genere mucho estrés. ¿Dónde está el equilibrio?

El doctor Martín Lesende señalaba en un trabajo ${ }^{6}$ que el cuidado de los nietos puede ser un sólido elemento de ayuda para los mayores, porque además de sentirse socialmente integrados, ofrece otras ventajas adicionales, ya que les puede ayudar a tener mejor salud y funcionamiento físico, ya que deben ir a buscarles al colegio; también favorece su funcionamiento mental, porque deben estar pendientes de los horarios, o incluso se pueden ver obligados a ayudarles en sus tareas escolares. Sin embargo, cuando estos abuelos acusan un desgaste emocional por tener que estar tantas horas cuidado a sus nietos, es porque la tarea se ha convertido en una obligación, en un deber que limita otras actividades o deseos de la persona mayor, excediendo el ritmo de exigencia física. Pasa entonces de ser un 'querer' a un 'tener que', y eso puede repercutir sobre su integridad física y emocional. Continúa el doctor Martín Lesende señalando que un factor de riesgo para ese estrés que puede afectar a los abuelos es lo que denomina "la delegación de responsabilidades e incluso de sentimientos”. Es bueno, señala, que ambas partes, abuelos y padres, busquen un punto medio de comprensión y entendimiento, que implique un esfuerzo conjunto por compartir las obligaciones y cuidados de acuerdo a las capacidades de ambos. La mayor parte de las veces, de llevarse a cabo correctamente, será una tarea con efectos positivos en el envejecimiento; en caso contrario, se generará una situación de estrés que podría tener efectos muy negativos sobre su salud.

Para avanzar en la mejora de calidad de vida de los abuelos cuidadores y prevenir posibles dependencias motivadas por el estrés que esos cuidados pudieran producirles, es necesario que, frente a este fenómeno, se propongan actuaciones corresponsables, en las que todos seamos partícipes. El fenómeno de la prevención de la dependencia y el cuidado de los menores no puede ser atendido sólo por las familias, como tampoco es el sector público el único responsable de dar soluciones. Todos tenemos algo

${ }^{6}$ Se trata de los resultados de un estudio presentado en el XXVIII Congreso de la Sociedad Española de Medicina de Familia y Comunitaria, que tuvo lugar en Madrid en noviembre de 2008, y a cuyos resultados se ha tenido acceso a través del Grupo de Atención al Mayor de la Sociedad Española de Medicina Familiar y Comunitaria. 
que hacer y debemos ofrecer soluciones a los problemas que se derivan de esta nueva realidad.

Para ello, se propone un decálogo de principios que, en nuestra opinión, deberían tomar en cuenta todos los responsables políticos y sociales a la hora de arbitrar nuevas actuaciones dirigidas a las familias que se ven forzadas a 'utilizar' a los abuelos como cuidadores a tiempo completo, y a todas aquellas en las que, entre sus miembros, se encuentra alguna persona dependiente.

1. Las actuaciones que faciliten el cuidado y apoyo a las personas en situación de dependencia deberán perseguir de manera prioritaria, y cuando esto sea posible, la permanencia de estas personas en el entorno familiar en el que desarrollen su vida habitualmente ${ }^{7}$. Esto exige la puesta en marcha de recursos y servicios, de naturaleza pública o privada, que ayuden a las familias a llevar a cabo estos cuidados. Por tanto, puede entenderse que las políticas de apoyo a la dependencia exigen necesariamente trabajar en el marco de la familia y deben perseguir, además, un objetivo claro, como es la defensa de algunos de sus derechos básicos, entre los que se encuentra la posibilidad de elegir la forma que considere más adecuada para el cuidado de los más débiles, de forma que no interfiera con otros derechos, como, por ejemplo, el de hacer compatible la jornada laboral con los cuidados familiares.

2. Las políticas y actuaciones - públicas o privadasdirigidas a dar cobertura y apoyo al cuidado de las personas dependientes debe ser entendidas como políticas sociales, pero también de lucha contra la discriminación:

Todas las personas nacen iguales y tienen el mismo derecho a la vida y al bienestar, a la educación y al trabajo, a vivir independientemente y a la participación activa en todos los aspectos de la sociedad. Por tanto, cualquier discriminación directa u otro trato discriminatorio negativo de una persona discapacitada [sin ser términos idénticos, podría añadirse 'dependiente’] es una violación de sus derechos. [...] se pide a los Gobiernos que, cuando sea necesario, adopten leyes o modifiquen su legislación para garantizar el acceso a estos y otros derechos de las personas discapacitadas [igualmente podría añadirse 'dependientes'] (Naciones Unidas, 1993).

7 En el artículo 3, de la Ley 39/2006, de 14 de diciembre, de Promoción de la Autonomía Personal y Atención a las Personas en Situación de Dependencia, se recogen los principios que regulan el tratamiento de los derechos que la norma genera, y entre ellos, en la letra i), se establece que deberá tratarse de lograr "la permanencia de las personas en situación de dependencia, siempre que sea posible, en el entorno en el que desarrollan su vida". Puede entenderse que se refiere, evidentemente, al ámbito familiar, ya que la forma más habitual de convivencia.
Aunque el marco jurídico vigente en nuestro país y en los restantes Estados de la Unión Europea en materia de derechos humanos asegura esta no discriminación, la realidad pone de manifiesto que siguen existiendo fuertes discriminaciones sociales, sobre todo cuando nos referimos a familias con personas dependientes. Estas discriminaciones derivan fundamentalmente de la imposibilidad de elegir el modo de atención a sus miembros más débiles. Las dificultades económicas, físicas o psíquicas y la carencia de apoyo externo para el desarrollo de sus funciones, obliga a los familiares, en muchas ocasiones, a renunciar a su papel de cuidadores, aun cuando expresan su deseo de hacerlo. Igualmente, también en ocasiones, los obliga a 'utilizar' a sus miembros más débiles -los abuelos- para cuidar a otros dependientes, como son los más pequeños. ¿No es esto una nueva forma de discriminación apoyada en la generosidad de unos pocos?

3. Una buena política pública de apoyo al cuidado de dependientes en el marco de las familias debería tratar de trabajar siempre con el menor coste económico posible, y con la máxima rentabilidad en términos sociales y de mejora de la calidad de vida; y para lograr esto, es evidente que resulta imprescindible contar con la familia. Las mejores políticas de apoyo a dependientes no son las que fijan como objetivo prioritario sacar a estas personas de su entorno familiar, sino las que facilitan todos los medios necesarios para poder atenderlas de la mejor manera posible, con dignidad, y lo que es más importante, que les permitan elegir la forma de hacerlo. Las mejores actuaciones públicas son las que tienen en cuenta no sólo los resultados cuantificables que se derivan de sus actuaciones -como el número de camas en residencias, o el número de plazas en centros de día-, sino que ponen en valor los efectos que esas actuaciones tienen sobre las relaciones humanas. Además, las redes familiares deben entenderse siempre como un elemento sustancial del tejido social de una sociedad civil en sentido amplio.

Por ello, la sustitución de una parte importante de sus funciones por el Estado o las administraciones públicas significaría el inicio de la desaparición de un tejido social importante y necesario, y por tanto, el inicio de una transformación clave para el futuro. No se trata de separar a los hijos de los padres, o a los nietos de sus abuelos, sino de ayudar a cada uno de ellos a desempeñar las funciones que les competen de la manera más eficiente posible. Parece igualmente importante recordar a los responsables políticos que los individuos siguen recurriendo a los cuidados informales incluso en aquellos países donde existe la posibilidad de utilizar servicios públicos universales, y esto es algo que deberá estar muy presente en las decisiones que se 
tomen sobre cuidado para la dependencia. Así, puede ocurrir que, en muchas ocasiones, ni la persona dependiente ni sus familiares concedan el mismo valor a la asistencia formal que a los cuidados informales, y acaben inclinándose por esta segunda opción, por considerar que ofrece un mayor bienestar para todos (Casado y López, 2001). Es en este caso en el deberían centrarse las principales actuaciones, prestando ayuda y apoyo a estas familias.

4. A pesar del reciente desarrollo de la legislación en materia de apoyo a la dependencia, las situaciones de discriminación que se producen en familias con personas dependientes son aún llamativas en el caso de España. Las políticas de familia dirigidas a ayudar a éstas son muy escasas, y de naturaleza y dimensión muy diferente en las diferentes comunidades autónomas, e incluso en los distintos ayuntamientos. Los índices de cobertura, u otros indicadores de los niveles de protección ofrecidos por los servicios de apoyo muestran importantes desigualdades territoriales. Sin embargo, dentro de esta diversidad y dispersión de medidas, se observa un elemento común, cual es la existencia de una mayor presencia de medidas de sustitución total de las familias, frente a otras que las ayuden a complementar y desempeñar más fácilmente su papel y sus funciones.

El primer tipo de ayudas públicas, las sustitutivas de la familia, son en muchas ocasiones imprescindibles, ya que hay situaciones en las que ésta no es capaz de atender con dignidad las necesidades de sus miembros más débiles, ya sea por el tipo de dependencia que presentan, la falta de recursos económicos, o la imposibilidad física o psíquica, por poner algún ejemplo. El segundo tipo de ayudas, que complementan el papel de la familia, son especialmente relevantes, a la vez que realmente escasas en nuestro país. Así, por ejemplo, puede comprobarse cómo los servicios de atención domiciliaria en España, que se vienen desarrollando desde hace más de tres decenios, y se recogen igualmente en el catálogo de servicios de la denominada Ley de Dependencia, aun habiendo experimentado importantes mejoras durante los últimos años, se han ido desarrollando de manera muy desigual, según el lugar de residencia de la persona dependiente. En estos casos, el nivel de protección indica la intensidad horaria con la que se ofrece, que oscila, de acuerdo con el grado de dependencia, entre 30 y 90 horas al mes. Además, el índice de cobertura de este servicio no llega al $5 \%$. No parece, por tanto, que se trate de un apoyo importante, y queda mucho por hacer en la mejora de este servicio. Este tipo de ayudas son menos costosas, ayudan a la creación de empleo y, sobre todo, a construir una sociedad más humana.

5. El fenómeno de la dependencia, como ya hemos visto, no es exclusivo de los tramos de edad más avanzados -de hecho, ésta se produce en todos ellos-, aunque no puede olvidarse que la evidencia empírica pone de manifiesto que el porcentaje de personas que soportan limitaciones en su capacidad funcional se incrementa conforme se consideran cohortes poblacionales de mayor edad, produciéndose un significativo aumento de esta dependencia a partir de los 80 años ${ }^{8}$. Por tanto, parece necesario que las actuaciones de apoyo tengan en cuenta esta realidad y pongan en marcha actuaciones diferenciadas en función de la edad de la persona dependiente y de los familiares que la cuidan. El aumento de la esperanza de vida lleva, como acabamos de señalar, a situaciones en las que las personas dependientes son, a su vez, cuidadoras, cuando son ellas mismas quienes necesitan de cuidados, ya que tienen limitaciones físicas o psíquicas que les dificultan su trabajo como cuidadoras, o simplemente se encuentran cansadas de haber vivido y cuidado a sus propios hijos.

6. El cuidado formal o informal de las personas dependientes siempre tiene un coste:

No hay ningún tipo de intervención que sea neutro. Tanto las intervenciones como su ausencia tienen efectos sobre la familia. Situados en el campo familiar como área de intervención pública, debemos aceptar que toda política familiar incide sobre las formas de vida y los comportamientos familiares e individuales y vehicula inevitablemente, explícita o implícitamente, preferencias normativas con respecto a tal o cual modelo de familia (Flaquer, 2000).

Este coste puede ser económico directo, o bien puede tratarse de un coste de oportunidad, que normalmente asumen las mujeres que se ven obligadas, en muchos casos, a dejar de hacer otras cosas -el mercado laboral o su proceso formativo, entre otras- para cuidar a los mayores Sin embargo, parece importante trabajar para lograr la implicación de todos y los responsables políticos debe recordar que:

[...] las familias no se niegan a cuidar, se trata de lograr un equilibrio entre derechos individuales y las obligaciones sociales de la atención [...] asegurando la oferta de servicios y encontrando el

\footnotetext{
${ }^{8}$ Admitiéndose que las predicciones demográficas que se vienen realizando fueran totalmente correctas, el argumento que se emplea para inferir el aumento futuro del número de personas mayores dependientes resulta cuestionable. El que la cantidad de ancianos aumente en el futuro, que es realmente lo único que señalan las proyecciones demográficas, y el que esto comporte el aumento en paralelo del número de personas dependientes dependerá de cómo evolucione la prevalencia de la incapacidad funcional. Admitir que ésta permanecerá inalterada, que es lo que plantea el argumento que permite extraer tan pesimistas conclusiones del envejecimiento demográfico, es sólo una hipótesis, y como tal, precisa de algún tipo de justificación.
} 
modo de distribuir socialmente el costo de la carga de las tareas de cuidado equitativamente entre hombres y mujeres, entre Estado, familia, comunidad y sector privado (Naciones Unidas, 1999).

De hecho, la propia Ley de Promoción de la Autonomía Personal y Atención a las Personas en Situación de Dependencia recoge, en su exposición de motivos, que es necesaria esta corresponsabilidad social, al señalar que es indudable que el tercer sector de acción social viene participando, desde hace años, en la atención a las personas en situación de dependencia, y apoyando el esfuerzo de las familias y de las corporaciones locales en este ámbito, y añade que estas entidades constituyen una importante malla social que previene los riesgos de exclusión de las personas afectadas.

7. A la hora de establecer una política pública, hace falta estimar los costes de su puesta en marcha, así como los de no llevarla a cabo. Y en esta evaluación, tendrán que tenerse en cuenta no sólo los costes económicos, sino también los sociales. Así, será preciso tener presentes dos consideraciones:

- Las políticas públicas proporcionan incentivos y desincentivos para que las conductas, orientadas estratégicamente, adopten una modalidad u otra. Así, por ejemplo, Inés Alberdi (2001), experta en temas de familia, afirmaba en 1986, al referirse a la Ley de Divorcio en España:

[...] los efectos de una ley tolerante son innegables: el comportamiento divorcista se hace menos costoso, la valoración social del divorcio se hace más tolerante y ello afecta a las decisiones individuales de los que se divorcian; las representaciones colectivas sobre el matrimonio cambian debido a las referencias legales, y aunque estos efectos simbólicos de las leyes van unidos a cambios culturales más amplios, es interesante contemplar su influjo.

Si aplicamos esta misma argumentación al tema que nos ocupa, podría afirmarse que priorizar la puesta en marcha y el desarrollo de políticas públicas que, en todos los casos, sustituyeran a la familia en el cuidado de sus miembros dependientes probablemente facilitaría comportamientos de esta naturaleza. Cabría pensar que, en el futuro, algunas familias podrían abandonar con más facilidad su responsabilidad de cuidadores, dejando en manos del Estado el cuidado de sus miembros más débiles. Sin embargo, el desempeño de esta responsabilidad familiar no puede llevarse a cabo a cualquier coste, como está ocurriendo en la actualidad con el 'uso excesivo' del recurso a los abuelos para el cuidado de nietos, cuando los padres no pueden, ya que se trata de una responsabilidad que no les compete.

- Evaluar los costes de las actuaciones en materia de cuidado y atención de las personas dependientes en el seno de la familia exige también reconocer la existencia de economías externas, al permitir una reducción de dichos costes -económicos y sociales- para la sociedad. Las familias, junto con el sector público, actúan como unidades que facilitan la redistribución de la renta entre personas y entre generaciones, actuando además como un colchón de los actuales Estados de bienestar europeos, sobre todo en los casos en que atienden a sus miembros dependientes. Además, la familia se configura como una unidad de obligaciones y derechos, que favorece la redistribución de la renta entre personas y generaciones, estabiliza la sociedad y proporciona una mayor cohesión social. Por ello, habrá que ayudar a las familias a eliminar todos los obstáculos que les impiden desempeñar su papel.

8. El sector público está obligado a garantizar los derechos de los niños y de todas las personas dependientes, su protección física, moral y material; y por el propio bien de éstos, la mejor manera de hacerlo es en el seno de sus familias cuando éstas pueden hacerlo, o sacándolos fuera de ellas en los casos en los que su permanencia sea imposible. Por ello, los poderes públicos y la sociedad en general deberían ayudar al cuidado y la atención de sus miembros dependientes, sin sustituirlos en su papel. Los Gobiernos deberían tener en cuenta que los servicios sociales aparentemente preferidos por las familias españolas son aquellos que las descargan, pero no las sustituyen (Pérez Díaz et al., 2000).

9. A la hora de organizar nuevas políticas de dependencia, es necesario establecer un nuevo pacto entre generaciones. El pacto actual está centrado, sobre todo, en la ayuda a las personas mayores, pero apoyado en el miedo: miedo a la vejez y a las consecuencias que ésta tendrá sobre los sistemas de pensiones, la mano de obra, o la inmigración. El nuevo pacto entre generaciones debería estar centrado en los jóvenes, y fundamentado en la confianza y en los valores humanos: es el momento de transformar todos los miedos en ganancias, y tener una visión positiva del futuro, apoyada en el equilibrio entre las generaciones. Hace falta recuperar el valor de las relaciones familiares como constructoras de una sociedad más estable y cohesionada. Pero esta recuperación exige no confundir los papeles y dejar a cada miembro de la familia ser lo que es. 
10. Las políticas de familia con personas dependientes deberán avanzar en una visión extensa de la nueva situación, sin limitarla a aspectos parciales, y deberán considerar que la familia es la parte del tejido social que mejor puede ofrecer a estas personas todos los apoyos que precisan, siempre y cuando pueda contar, para ello, con la ayuda de la sociedad y de los poderes públicos. La puesta en marcha de nuevas políticas de dependencia pasa por arbitrar medidas de apoyo a la familia, que tendrían que ir precedidas de una revisión de los tópicos que proponga ordenar las principales áreas temáticas que tienen que ver con dichas políticas y que deberían incluirse en las agendas sociales de todos los Estados europeos: políticas de familia y mercado de trabajo, políticas de familia y crecimiento económico sostenido, entre otras. No puede continuar el debate sobre las políticas de familia y dependencia, iniciado en España hace muy pocos años, centrado casi exclusivamente en la necesidad de lograr ayudas económicas directas de manera universalizada y crear plazas residenciales. ¿Cuáles son los resultados alcanzados hasta ahora por estas actuaciones públicas? ¿Qué efectos están teniendo sobre las familias que reciben algún tipo de ayuda? Es preciso avanzar en la evaluación de este tipo de políticas, para poder dar respuesta a las nuevas necesidades que se nos plantean.

En definitiva, el objetivo de las políticas de familia y dependientes deberán reconocer el valor social y económico de la familia, los niños, los ancianos y, especialmente, de sus miembros dependientes, aunque estos colectivos de población no sean directamente productivos en términos económicos. Deberán organizarse políticas de conciliación de la vida familiar y laboral que no los consideren como 'obstáculos' para el acceso y la permanencia de la mujer en el mercado laboral. Además, hay que tener presente que la puesta en marcha de ayudas a las familias con personas dependientes puede ser una fuente generadora de nuevos puestos de trabajo $\mathrm{y}$, por tanto, de nuevos yacimientos de creación de empleo, pero sobre todo, de una sociedad más humana. 


\section{Bibliografía}

ALBERDI, I. (2001): "Padres, madres e hijos ante los nuevos valores de la familia española”, en DURÁN, Ma Á., Estructura y cambio social, Madrid, Centro de Investigaciones Sociológicas.

BÁDENES PLÁ, N.; y LÓPEZ LÓPEZ, Maㅡ. (2010): Doble dependencia: abuelos que cuidan nietos en España, colección Estudios y Monografías, Pamplona, Aranzadi.

- (2009): "How much grandparents take care of grandchildren in Europe? An analysis from SHARE data". Comunicación presentada a la 2nd National Research Conference on Child and Family Programs and Policy, Bridgewater, 16-17 de julio.

DEL CAMPO, S.; y NAVARRO, M. (1985): Análisis sociológico de la familia española, Barcelona, Ariel.

CASADO, D.; y LÓPEZ i CASASNOVAS, G. (2001): Vejez, dependencia y cuidados de larga duración. Situación actual y perspectivas de futuro, colección Estudios Sociales, nำ6, Barcelona, Fundación La Caixa.

DONATI, P. (2003): Manual de sociología de la familia, Pamplona, Eunsa.

FLAQUER, L. (2000): La política familiar desde una perspectiva comparada, Barcelona, Fundación La Caixa.
HANK, K.; y BUBER, I. (2007): Grandparents caring for their grandchildren: Findings from the 2004 survey of health, ageing and retirement in Europe, serie MEA Discussion Papers, nํㅜ 127, Mannheim, Mannheim Research Institute for the Economics of Aging [<http://madoc.bib.unimannheim.de/madoc/volltexte/2007/1558/ pdf/meadp_127_07.pdf)].

LÓPEZ LÓPEZ, Mำ T. (coord.) [2008]: Análisis de datos en la investigación social de la familia, Madrid, Cinca.

NACIONES UNIDAS (1999): El corazón invisible: la atención y la economía mundial, Madrid, Mundi-Prensa.

- (1993): Conferencia Mundial de Derechos Humanos. Viena, 14 a 25 de junio de 1993. Declaración y Programa de Acción de Viena, Viena, Naciones Unidas [<http://www.unhchr.ch/huridocda /huridoca.nsf/\%28Symbol\%29/A.CONF.157.23 .Sp?Opendocument>].

PÉREZ-DÍAZ, V.; CHULIÁ, E.; y VALIENTE, C. (2000): La familia española en el año 200o, colección Economía Español, Madrid, Fundación Argentaria; Visor.

SANCHO CASTIELLO et al. (2007): "Las personas mayores y las situaciones de dependencia”, Revista del Ministerio de Trabajo e Inmigración, noㅜㅇ, págs. 13-43. 
